\title{
Compatible solutes: the key to Listeria's success as a versatile gastrointestinal pathogen?
}

Roy D Sleator ${ }^{1,2^{*}}$, Colin Hill ${ }^{2}$

\begin{abstract}
Recently we reported a role for compatible solute uptake in mediating bile tolerance and increased gastrointestinal persistence in the foodborne pathogen Listeria monocytogenes[1]. Herein, we review the evolution in our understanding of how these low molecular weight molecules contribute to growth and survival of the pathogen both inside and outside the body, and how this stress survival mechanism may ultimately be used to target and kill the pathogen.
\end{abstract}

The Gram-positive foodborne pathogen Listeria monocytogenes is a causative agent of gastroenteritis [2,3] and in severe cases, listeriosis, which ranges from a mild flulike illness to meningitis, or as infection of the foetus in pregnant women. Described as a 'Jekyll and Hyde' character [4], L. monocytogenes exhibits saprophytic and parasitic lifestyles; residing both in decaying plant matter in the soil [5], and as a transient inhabitant of the gastrointestinal (GI) tract of several animal species including man [6].

This physiological robustness (the ability to adapt to a variety of different environments) results from an ability to sense and respond rapidly to changes in the external environment [7]; a response mediated by a complex arsenal of genes encoding proteins linked to survival both within and outside of the host [8]. One such response, which has been the focus of significant research efforts in our laboratories, is the accumulation (either by transport [9] or synthesis $[10,11]$ ) of compatible solutes low-molecular-weight molecules which when amassed to high intracellular concentrations help ameliorate the effects of several stressful conditions [12].

The preferred compatible solutes for the majority of bacteria and those most effective in $L$. monocytogenes are the trimethylammonium compounds; betaine, which is found in relatively high concentrations in foods of plant origin $[13,14]$ and carnitine, which is most abundant in animal tissues [15]. Functional genomic studies,

\footnotetext{
* Correspondence: roy.sleator@cit.ie

'Department of Biological Sciences, Cork Institute of Technology, Rossa

Avenue, Bishopstown, Cork, Ireland

Full list of author information is available at the end of the article
}

coupled with in silico analysis of genome sequences [8], revealed four putative compatible solute uptake systems in L. monocytogenes: BetL and Gbu (dedicated to betaine uptake), OpuC (which transports carnitine and to a lesser extent betaine) and OpuB which was designated as a putative compatible solute uptake system solely on the basis of sequence homology to the betaine uptake system BusA (OpuA) of Lactococcus lactis (Figure 1) [16].

Although initially identified as osmoprotective compounds (facilitating growth of the pathogen in low $\mathrm{a}_{\mathrm{w}}$ environments), subsequent studies revealed a multitude of beneficial effects arising from compatible solute accumulation; including protection against desiccation [17], low temperature [18] and high pressure [19] stresses encountered in foods and/or food processing environments. However, in addition to facilitating growth and survival in external environments, we have revealed a significant role for OpuC (and more specifically carnitine uptake) in enabling growth and survival of the pathogen within the host GI tract [15]. Inactivating the opuC gene, and thus reducing carnitine uptake, resulted in a significant reduction in the ability of $L$. monocytogenes to colonize the upper small intestine and cause subsequent systemic infection following oral inoculation. Given that the osmolarity of the gut (equivalent to $0.3 \mathrm{M} \mathrm{NaCl}$ ) represents an osmotic challenge to the pathogen and that carnitine is the most abundant compatible solute in that environment ( 0.05 to $0.2 \%$ on a fresh weight basis), this finding was perhaps predictable. But is this the full story? Is osmotolerance alone responsible for the increased gut colonization and persistence ascribed to opuC in 


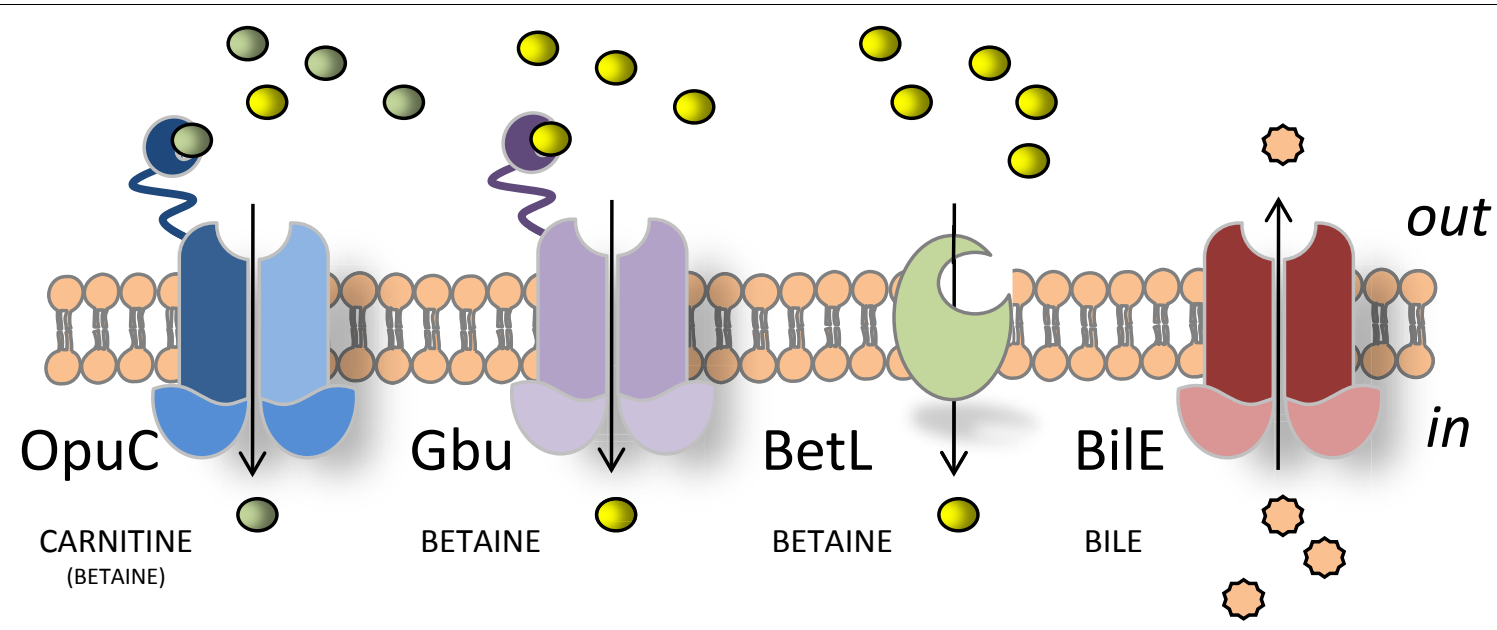

Figure 1 While in silico analysis of the listerial genome initially identified four putative compatible solute uptake systems (BetL, Gbu, OpuC and OpuB) [8], functional analysis revealed that OpuB is in fact a Bile exclusion system (hence its reincarnation as BilE).

L. monocytogenes, or indeed betL when heterologously expressed in Bifidobacterium breve? [20]

\section{Double, Double, BilE and Trouble}

Despite exhibiting significant sequence similarity to members of the betaine carnitine choline transporter (BCCT) family (hence the original Opu nomenclature for osmoprotectant uptake) OpuB has to date failed to display any appreciable compatible solute uptake, suggesting an alternative role for the protein. Indeed, a more detailed bioinformatic analysis of the sequence revealed two ATP-dependent bile acid permease signature sequences in the first gene of the operon [21]. Common to bile efflux pumps these motifs suggested a possible role for OpuB in listerial bile tolerance. Produced in the liver, stored interdigestively in the gall bladder and secreted into the duodenum, bile represents a far more immediate challenge to the pathogen than osmolarity and, as such, is the foremost innate immune defense mechanism of the upper small intestine [22]. Phenotypic analysis of the in silico findings using radiolabelled bile efflux studies revealed that OpuB did in fact function as a bile exclusion system - actively extruding bile from the bacterial cell - a phenotype which significantly modulates the virulence potential of the pathogen. That OpuB functions as a bile tolerance locus, as opposed to an osmolyte uptake system as was originally believed, led to its reincarnation as BilE (for Bile Exclusion) [21].

Notwithstanding its newly ascribed function as a bile resistance mechanism, the similarity of BilE to compatible solute uptake systems, together with the fact that it is transcriptionally regulated by the alternative sigma factor $\sigma^{\mathrm{B}}$ [22], along with BetL, Gbu and OpuC [8], suggested a common function for all four proteins; if not in osmotolerance then perhaps in bile tolerance...

In support of this hypothesis a systematic analysis of strains with mutations in the primary compatible solute uptake systems also revealed roles for $\mathrm{OpuC}$, and to a lesser extent BetL, in resisting the acute toxicity of bile [1]. Furthermore, real-time gene expression profiling in the presence of bile, using a lux gene reporter system, revealed that both betL and opuC are induced by bile. Interestingly, while opuC is more highly expressed in vitro, betL exhibits higher expression levels in vivo. Significantly, in addition to BetL, Gbu, OpuC and BilE; $\sigma^{\mathrm{B}}$ has also been shown to regulate the expression of $\mathrm{BSH}$ (a bile detoxification system) and, as such, may act as the master regulator of bile tolerance in the GI tract.

\section{Listeria's Achilles heel?}

The fact that compatible solutes protect $L$. monocytogenes at all stages of it lifecycle, from saprophyte to parasite, makes them a potentially important target for controlling the pathogen. Regulating the levels and/or availability of specific compatible solutes in high risk foods, e.g. baby formula (where carnitine is often added as a vitamin-like supplement), is an obvious first step [23]. While pathogen control during infection may be mediated by 'smugglin technology' - the application of toxic analogues - bactericidal compounds which, because they resemble compatible solutes, are accumulated by and ultimately kill the pathogen. Another approach which has received considerable attention in recent times is based on the patho-biotechnology concept [24-29] - the application of pathogen derived virulence or stress survival factors for the construction of improved pharmabiotic strains as biological control agents [30]. These alternative approaches to pathogen control, 
borne out of a clear understanding of how the pathogen adapts to its specific environment (both inside and outside the host) may ultimately provide us with a viable alternative to antibiotics for controlling old adversaries such as $L$. monocytogenes, as well as new and emerging pathogens the so called "super bugs" [26,28].

\section{Acknowledgements}

The authors wish to acknowledge the continued financial assistance of the Health Research Board (HRB) and the Alimentary Pharmabiotic Centre (APC) through funding by Science Foundation Ireland (SFI). This letter is based on a manuscript entitled Compatible solutes: A listerial passe-partout? In Gut Microbes 1(2), 77-79.

\section{Author details}

'Department of Biological Sciences, Cork Institute of Technology, Rossa Avenue, Bishopstown, Cork, Ireland. ${ }^{2}$ Alimentary Pharmabiotic Centre, University College Cork, College Road, Cork, Ireland.

\section{Authors' contributions}

RDS and $\mathrm{CH}$ conceived of the study and drafted the manuscript. All authors read and approved the final manuscript.

\section{Competing interests}

The authors declare that they have no competing interests.

Received: 6 December 2010 Accepted: 10 December 2010 Published: 10 December 2010

\section{References}

1. Watson D, Sleator RD, Casey PG, Hill C, Gahan CG: Specific osmolyte transporters mediate bile tolerance in Listeria monocytogenes. Infect Immun 2009, 77:4895-4904

2. Sleator RD, Watson D, Hill C, Gahan CG: The interaction between Listeria monocytogenes and the host gastrointestinal tract. Microbiology 2009, 155:2463-2475

3. Sleator RD, Hill C: A novel role for the LisRK two-component regulatory system in listerial osmotolerance. Clin Microbiol Infect 2005, 11:599-601.

4. Gray MJ, Freitag NE, Boor KJ: How the bacterial pathogen Listeria monocytogenes mediates the switch from environmental Dr. Jekyll to pathogenic Mr. Hyde. Infect Immun 2006, 74:2505-2512.

5. Freitag NE, Port GC, Miner MD: Listeria monocytogenes - from saprophyte to intracellular pathogen. Nat Rev Microbiol 2009, 7:623-628.

6. Sleator RD, Francis GA, O'Beirne D, Gahan CG, Hill C: Betaine and carnitine uptake systems in Listeria monocytogenes affect growth and survival in foods and during infection. J Appl Microbiol 2003, 95:839-846.

7. Sleator RD, Wood JM, Hill C: Transcriptional regulation and posttranslational activity of the betaine transporter BetL in Listeria monocytogenes are controlled by environmental salinity. J Bacterio/ 2003, 185:7140-7144

8. Sleator RD, Gahan CG, Hill C: A postgenomic appraisal of osmotolerance in Listeria monocytogenes. Appl Environ Microbiol 2003, 69:1-9.

9. Wemekamp-Kamphuis HH, Wouters JA, Sleator RD, Gahan CG, Hill C, Abee T: Multiple deletions of the osmolyte transporters BetL, Gbu, and OpuC of Listeria monocytogenes affect virulence and growth at high osmolarity. Appl Environ Microbiol 2002, 68:4710-4716.

10. Sleator RD, Gahan CG, Hill C: Identification and disruption of the proBA locus in Listeria monocytogenes: role of proline biosynthesis in salt tolerance and murine infection. Appl Environ Microbiol 2001, 67:2571-2577.

11. Sleator RD, Gahan CG, Hill C: Mutations in the listerial proB gene leading to proline overproduction: effects on salt tolerance and murine infection. Appl Environ Microbiol 2001, 67:4560-4565.

12. Sleator RD, Hill C: Bacterial osmoadaptation: the role of osmolytes in bacterial stress and virulence. FEMS Microbiol Rev 2002, 26:49-71.

13. Sleator RD, Gahan CGM, O'Driscoll B, Hill C: Analysis of the role of betL in contributing to the growth and survival of Listeria monocytogenes LO28. Int J Food Microbiol 2000, 60:261-268.
14. Sleator RD, Gahan CG, Abee T, Hill C: Identification and disruption of BetL, a secondary glycine betaine transport system linked to the salt tolerance of Listeria monocytogenes LO28. App/ Environ Microbiol 1999, 65:2078-2083.

15. Sleator RD, Wouters J, Gahan CG, Abee T, Hill C: Analysis of the role of OpuC, an osmolyte transport system, in salt tolerance and virulence potential of Listeria monocytogenes. Appl Environ Microbiol 2001, 67:2692-2698.

16. Obis D, Guillot A, Gripon JC, Renault P, Bolotin A, Mistou MY: Genetic and biochemical characterization of a high-affinity betaine uptake system (BusA) in Lactococcus lactis reveals a new functional organization within bacterial ABC transporters. J Bacteriol 1999, 181:6238-6246.

17. Dreux N, Albagnac C, Sleator RD, Hill C, Carlin F, Morris CE, Nguyen-the C: Glycine betaine improves Listeria monocytogenes tolerance to desiccation on parsley leaves independent of the osmolyte transporters BetL, Gbu and OpuC. J Appl Microbiol 2008, 104:1221-1227.

18. Wemekamp-Kamphuis HH, Sleator RD, Wouters JA, Hill C, Abee T: Molecular and physiological analysis of the role of osmolyte transporters BetL, Gbu, and OpuC in growth of Listeria monocytogenes at low temperatures. Appl Environ Microbiol 2004, 70:2912-2918.

19. Smiddy M, Sleator RD, Patterson MF, Hill C, Kelly AL: Role for compatible solutes glycine betaine and L-carnitine in listerial barotolerance. Appl Environ Microbiol 2004, 70:7555-7557.

20. Sheehan VM, Sleator RD, Hill C, Fitzgerald GF: Improving gastric transit, gastrointestinal persistence and therapeutic efficacy of the probiotic strain Bifidobacterium breve UCC2003. Microbiology 2007, 153:3563-3571.

21. Sleator RD, Wemekamp-Kamphuis HH, Gahan CG, Abee T, Hill C: A PrfAregulated bile exclusion system (BilE) is a novel virulence factor in Listeria monocytogenes. Mol Microbiol 2005, 55:1183-1195.

22. Begley M, Sleator RD, Gahan CG, Hill C: Contribution of three bileassociated loci, bsh, pva, and bt|B, to gastrointestinal persistence and bile tolerance of Listeria monocytogenes. Infect Immun 2005, 73:894-904.

23. Sleator RD, Banville N, Hill C: Carnitine enhances the growth of Listeria monocytogenes in infant formula at 7 degrees C. J Food Prot 2009, 72:1293-1295.

24. Sleator RD, Hill C: Patho-biotechnology: using bad bugs to do good things. Curr Opin Biotechnol 2006, 17:211-216.

25. Sleator RD, Hill C: Patho-biotechnology; using bad bugs to make good bugs better. Sci Prog 2007, 90:1-14.

26. Sleator RD, Hill C: Battle of the bugs. Science 2008, 321:1294-1295.

27. Sleator RD, Hill C: Engineered pharmabiotics with improved therapeutic potential. Hum Vaccin 2008, 4:271-274.

28. Sleator RD, Hill C: Designer probiotics: a potential therapeutic for Clostridium difficile? J Med Microbio/ 2008, 57:793-794

29. Sleator RD, Hill C: 'Bioengineered Bugs' - a patho-biotechnology approach to probiotic research and applications. Med Hypotheses 2008, 70:167-169.

30. Culligan EP, Hill C, Sleator RD: Probiotics and gastrointestinal disease: successes, problems and future prospects. Gut Pathog 2009, 1:19.

doi:10.1186/1757-4749-2-20

Cite this article as: Sleator and Hill: Compatible solutes: the key to Listeria's success as a versatile gastrointestinal pathogen?. Gut Pathogens 2010 2:20.

\section{Submit your next manuscript to BioMed Central and take full advantage of:}

- Convenient online submission

- Thorough peer review

- No space constraints or color figure charges

- Immediate publication on acceptance

- Inclusion in PubMed, CAS, Scopus and Google Scholar

- Research which is freely available for redistribution 